ARENAS Pastor y Gustavo PORINI, Las aves en la vida de los tobas del oeste de la provincia de Formosa (Argentina)

\title{
Cecilia Gómez
}

\section{(2) OpenEdition}

12 Journals

Edición electrónica

URL: https://journals.openedition.org/jsa/11605

DOI: 10.4000/jsa. 11605

ISSN: 1957-7842

Editor

Société des américanistes

\section{Edición impresa}

Fecha de publicación: 5 diciembre 2010

Paginación: 316-319

ISSN: 0037-9174

\section{Referencia electrónica}

Cecilia Gómez, "ARENAs Pastor y Gustavo poRINI, Las aves en la vida de los tobas del oeste de la provincia de Formosa (Argentina)», Journal de la Société des américanistes [En línea], 96-2 | 2010, Publicado el 22 julio 2010, consultado el 04 septiembre 2022. URL: http://journals.openedition.org/jsa/11605 ; DOI: https://doi.org/10.4000/jsa. 11605

Este documento fue generado automáticamente el 4 septiembre 2022.

All rights reserved 


\title{
ARENAS Pastor y Gustavo PORINI, Las aves en la vida de los tobas del oeste de la provincia de Formosa (Argentina)
}

\author{
Cecilia Gómez
}

\section{REFERENCIA}

ARENAS Pastor y Gustavo PORINI, Las aves en la vida de los tobas del oeste de la provincia de Formosa (Argentina), Editorial Tiempo de Historia, Asunción, 2009, 300 p.

1 Las aves tienen una gran vigencia simbólica en la vida social de los tobas del oeste formoseño (familia lingüística guaycurú). Para desentrañar este cúmulo de significaciones Arenas y Porini llevan a cabo una investigación que definen como « etnoornitológica», cuyo objetivo principal es analizar las formas en las cuales los tobas «nombran, perciben, conciben, utilizan y se relacionan con las aves de su entorno natural » (p. 17). Para ello los autores trabajan a partir de una perspectiva tanto emic como etic. La gran cantidad de datos presentados sobre las aves es de primera mano, recabada durante un extenso trabajo de campo entre los tobas que no sólo debió sostenerse en las técnicas tradicionales de observación participante sino también en actividades como el avistaje ornitológico, la recolección de material biológico, la observación de plumajes y de pieles y el trabajo sistemático con láminas, gráficos y fotografías. A la información documentada de esta forma se sumó, luego, un intenso trabajo de gabinete, cuyo resultado es una exhaustiva descripción de una gran cantidad de aves en contexto. En este sentido, los autores no sólo buscan sintetizar una gran cantidad de datos y testimonios, sino también dejar un registro material sobre el tema que resulte de utilidad para un público lo más amplio posible: para los tobas, para lectores interesados, para trabajadores sociales, educadores, profesionales y académicos de distintas disciplinas. Según señalan los autores, esta intención obedece particularmente a una preocupación explícita de los tobas más ancianos, a quienes les 
inquieta que los conocimientos que poseen sobre su historia y su forma de vida se pierdan por no quedar registrados de forma accesible para las nuevas generaciones.

2 Arenas y Porini detallan rigurosamente los métodos utilizados para recabar los datos de campo así como también el material biológico. En la primera parte, la obra ubica al lector en el contexto de los tobas (también llamados «tobas-pilagá» o «tobas de Sombrero Negro » en la literatura, por ejemplo en Métraux 1937 o en Arenas 2003), su organización social y su entorno natural (el hábitat del río Pilcomayo, la vegetación y la fauna, los cambios ambientales). Se ofrece una primera caracterización de las aves tomando en cuenta las fuentes precedentes, su presencia en la narrativa oral toba y en los estudios socioculturales. Parte de esa información es retomada en los apartados que siguen, referidos específicamente a las aves. De hecho, el mayor mérito del libro es el rastreo de la imbricada vinculación entre la vida social y el plano ornitológico, así como también entre éste, el medioambiente y el resto de los seres que lo pueblan. Los autores sostienen que en las sociedades indígenas chaqueñas «... el mundo viviente se revela como un todo y las alusiones referidas a plantas y animales está íntimamente superpuestas y entrelazadas. Es así que la separación en temas o subtemas, delimitando o acotando, así como la elección de una encuesta orientada hacia puntos específicos, es un artificio del investigador » (p. 19).

3 La parte del libro que contiene los hallazgos específicos sobre las aves se titula « Resultados ». Su disposición no se limita a un listado analítico de cada una de ellas, con sus respectivos nombres en lengua toba, sino que despliega una impresionante cantidad de datos sobre la base de dos ejes expositivos. Por una parte, se indagan algunos aspectos específicos de la cultura toba que se ven relacionados a las aves de un modo general; de esta forma, se puede apreciar el abigarrado entretejido de significados atribuidos por los tobas a las aves. Por otra parte, en el apartado titulado « Repertorio de aves » se presenta un listado de las aves con sus respectivos nombres en idioma; allí se compila toda la información cultural que los autores reunieron sobre cada una de las especies otorgando una marcada preponderancia a la etnociencia toba, y por tanto obviamente basada en la información que ofrecieron los informantes. Los autores dividen este listado en aquellas aves que identificaron y aquellas que no. Lo interesante es que, en esta segunda parte, la información se ofrece de forma que puede ser consultada de diferentes maneras según el interés o el criterio del lector. Por ejemplo, si a éste le interesa el papel de las aves en la cultura material puede dirigirse al correspondiente apartado temático sin necesidad de realizar un recorrido por cada una de las aves descriptas; pero si, por el contrario, se interesa por un ave en particular, puede acceder a la entrada respectiva y enterarse de las prácticas y representaciones concretas con las cuales los tobas la asocian. Hacia el final del libro se ofrece un breve balance analítico de los resultados obtenidos por medio del ordenamiento de los datos en varias tablas recapitulativas que brindan una visión más cuantitativa y sintética de parte de los temas abordados. Asimismo, los apéndices ofrecen tablas con la nomenclatura de la morfología de las aves, un detallado índice analítico y numerosas fotografías.

Es notorio que los autores no se embarcan en discusiones teóricas y que su objetivo principal es dar cuenta lo más fielmente posible de los datos relevados en el campo. Por lo tanto, el libro está plagado de detalles de gran interés para todo aquel que trabaje en el área cultural del Gran Chaco. Por citar tan sólo un ejemplo, se describe el interesante papel cosmológico que desde la perspectiva toba cumple el $m a^{\prime}$ ñik o suri (Rhea americana), sin duda el ave con más presencia en las representaciones, que tiene la 
particularidad de estar relacionado sistemáticamente con características socialmente positivas: la domesticación, la alimentación, la medicina, la fabricación de bienes materiales (pp. 137-140, 246). Para los autores, el $m a^{\prime} \tilde{n} i k$ « ... sin ninguna duda es el ave más importante para los tobas, ya sea por su interés para el sustento como por sus connotaciones en diversos aspectos de su vida social». Desde una perspectiva etnoastronómica podríamos agregar por nuestra cuenta que el máñik también se relaciona significativamente con el plano celeste: como otros grupos de lengua guaycurú, en determinados momentos del ciclo anual los tobas identifican la forma astral del ave en las partes oscuras de la vía láctea, componiendo un asterismo que atraviesa gran parte del firmamento (Lehmann-Nitsche 1924-1925, pp.192-194; Gómez 2010, pp. 124-126, 253).

5 Arenas y Porini reconocen que « ... un estudio meticuloso de la nomenclatura biológica vernácula y su etnosistemática requiere aún un largo camino previo por recorrer, ya que además son indispensables mayores informaciones en el campo de la etnología » (pp. 124-127). Por lo tanto, califican a este emprendimiento como " preliminar». Sin embargo, hay que decir que la riqueza de la información presentada es realmente destacable. No sólo por los datos que sientan las bases de un trabajo sólido sobre los nombres, los sistemas clasificatorios vernáculos y sus lógicas subyacentes, sino también porque ponen de relieve las disonancias o discrepancias en el acceso a ese mismo saber. En efecto, el libro demuestra que el saber etno-ornitológico no es uniforme entre los tobas, que hay diversas interpretaciones y que existen diversas formas de acceso al conocimiento entre los distintos miembros del grupo. Asimismo, el libro despliega esta masa empírica cumpliendo el objetivo de garantizar un fácil acceso al público no especializado sin perder por ello especificidad temática, detalle fáctico ni seriedad analítica. Lo dicho, en consecuencia, basta para afirmar que esta obra se transformará en una referencia de consulta indispensable para todo aquel que quiera indagar sobre la etno-ornitología chaqueña, sobre la biología regional, sobre la cultura toba y en un nivel más general sobre la lógica clasificatoria de las sociedades indígenas chaqueñas.

\section{BIBLIOGRAFÍA}

\section{ARENAS Pastor}

2003 Etnografía y alimentación entre los toba-ñachilamoleek y wichí-lhuku'tas del Chaco central (Argentina), Dunken, Buenos Aires.

GóMEz Cecilia

2010 Etnoastronomía, cosmovisión y frontera entre los toba del Oeste formoseño (toba pilagá), tesis de doctorado en ciencias sociales, Universidad de Buenos Aires, Buenos Aires.

LEHMANN-NITSCHE Robert

1924-1925 « La astronomía de los tobas (segunda parte) », Revista del Museo de La Plata, 28, pp. 181-209. 
MÉTRAUX Alfred

1937 « Études d'ethnographie Toba-Pilagá (Gran Chaco) », Anthropos, 32 (171-194), pp. 378-401.

\section{AUTORES}

\section{CECILIA GÓMEZ}

Universidad de Buenos Aires, Argentina 